Actualidades en Psicología,

2003, Vol. 19, No. 106, 113-130

\title{
Análisis epistémico del modelo biológico para explicar el origen de la esquizofrenia
}

\author{
Silvio Bolaños Salvatierra ${ }^{(*)}$ \\ Universidad de Costa Rica
}

Resumen. En este artículo se revisa el estado actual de los estudios que tratan de explicar genéticamente el comportamiento esquizofrénico. Entre éstos, se destacan dos tipos de investigaciones, las que tratan de correlacionar estadísticamente a algunos genes con la enfermedad y los meta-análisis de adopción que han generado el descubrimiento de la esquizotaxia, la cual consiste en una combinación de síntomas negativos y trastornos neuropsicológicos que afecta a todos los parientes del esquizofrénico. Se propone un modelo alternativo, que integra lamarquistamente los factores genéticos, para comprender dialécticamente la enfermedad. Se analizan los modelos de investigación del comportamiento desde una perspectiva epistemológica. Se reconocen los méritos biologistas: la resolución del dualismo mente-cuerpo y sus aportes para la disolución del problema salud-enfermedad. Se señalan sus limitaciones (oposición menteambiente y materia-información), las cuáles, se proponen también, como los retos que deberán enfrentar y superar las ciencias biológicas y sociales.

Palabras clave: esquizofrenia, esquizotaxia, genética, neuropsicología, psicocibernética.

Abstract. In this article the current state of the studies is revised according to try to explain the schizophrenic behavior genetically. Among these, stand out two types of investigations, those try to correlate statistically some genes with the illness and the adoption meta-analysis that have generated the discovery of the schizotaxia, which consists in a combination of negative symptoms and neuropsychological dysfunctions that affect all the relatives of the schizophrenic patient. An alternative model proposes to integrate lamarckianly the genetics factors, to understand dialectically the illness. The models of investigation of the behavior are analyzed from an epistemological perspective. The biologicist merits are recognized: the resolution of the dualism mind-body and their contributions for the break up of the problem health-illness. Their limitations are pointed out (opposition mind-environment and matterinformation), those are intended also, as the challenges that will face and overcome the biological and social sciences.

Key Words: Schizophrenia, schizotaxia, genetics, neuropsychology, cybernetic psychology

(*) Dirección postal: Escuela de Psicología, Ciudad Universitaria Rodrigo Facio, San Pedro, San José, Costa Rica. Ce: josalvat@racsa.co.cr 


\section{Introducción}

Hasta la fecha el término esquizofrenia se refiere fundamentalmente a una serie de manifestaciones psicopatológicas no patognomónicas que se presentan en un determinado curso temporal (Obiols y Obiols, 1989). La vaguedad de esta definición no ha desaparecido a pesar de su actual formato operativo y del importantísimo aporte hecho por la Asociación Psiquiátrica Americana, a través de las sucesivas revisiones de su Manual Diagnóstico y Estadístico de los Trastornos Mentales (DSM), puesto que el valor clínico del diagnóstico no ha podido superar aún las limitaciones causadas por el uso de criterios exclusivamente sintomáticos.

Esto, sin embargo, no ha sido ningún obstáculo para que la comunidad científica mundial acepte que la esquizofrenia es una enfermedad neuropsicológica de graves consecuencias. En aquellos que se encuentran afectados por esta entidad, el cerebro fracasa en funciones como las de diferenciar correctamente entre lo subjetivo y lo objetivo; fracasa en la asimilación de estímulos sociales y en su utilización para lograr una adecuada adaptación al medio; y falla también, en la integración del conjunto de funciones superiores que determina la posesión de una identidad estable.

Cuando estas características se suman a la ausencia de datos inequívocos de laboratorio y de gabinete, se comprende cómo han existido y continúan existiendo grandes dificultades para lograr una definición por consenso y, por ende, se entiende cómo, a través de la historia, se ha mantenido un encendido debate ideológico (Obiols y Obiols, 1989).

Las múltiples interpretaciones, ensanchamientos, acotaciones y cambios de énfasis que ha sufrido el concepto de esquizofrenia a través del tiempo han sido los insumos de la polémica que continúa escenificándose entre dos clases de epistemología: la lineal progresiva, que es atomista, reduccionista, anticontextual y que se atiene a una lógica que se centra en las combinaciones entre elementos aislados; y la recurrente, la cual pone el acento en la ecología y en los sistemas totales y, por lo cual, es congruente con la interrelación, la complejidad y el contexto (Keeney, 1991).

Aunque, como se verá más adelante, las diferencias entre estos contendientes se han ido reduciendo en forma significativa, éstas no han desaparecido y se encuentran, algunas, en el terreno de la filosofía de la ciencia; y otras, en el campo de la ética.

Consecuentemente con todo lo anotado antes, los objetivos de este artículo son: a) describir el estado actual de los estudios que tratan de explicar genéticamente el comportamiento esquizofrénico; b) proponer un modelo recurrente, que articule dialécticamente la genética con el ambiente a la hora de comprender la esquizofrenia; y c) realizar un análisis crítico acerca de la problemática epistemológica y ética implícita en cualquier formulación no cibernética acerca de la conducta humana y sus trastornos. 


\section{Panorama actual de la genética de la esquizofrenia}

Las investigaciones genéticas relacionadas con la etiología de la esquizofrenia se han focalizado en tópicos como: la herencia compartida entre consanguíneos (especialmente entre los gemelos monocigóticos), la adopción de recién nacidos con antecedentes familiares de esquizofrenia y su evolución posterior, la estructura de los genes candidatos y el ligamiento de algún fragmento de éstos con el trastorno y, últimamente, la transmisibilidad de la esquizotaxia. A continuación se hace una revisión de cada uno de estos aspectos.

\section{Los estudios de consanguinidad y los nacimientos monocigóticos}

Los estudios sobre consanguinidad han comparado la incidencia de esquizofrenia en parientes de un caso índice, con la incidencia de este mismo trastorno en familias de control (Africa, Freudenreich y Schwartz, 2001; Herrera, 2003). Con base en estos datos, se ha observado que la incidencia de esquizofrenia aumenta según la existencia de consanguinidad más estrecha. Así, cuando la similitud genética es del 50\% (como entre hermanos) la incidencia oscila entre 8\% y 14\%; pero cuando la similitud es mayor (como entre gemelos monocigóticos), la incidencia se eleva hasta alcanzar entre 39\% y 47\% (López et al, 2002).

Sin embargo, aunque según estos datos, pueda parecer evidente la influencia genética, simultáneamente estos mismos números han contribuido a relativizar el aserto de tal influencia. La mejor prueba del componente hereditario de la esquizofrenia, es también la mejor prueba de lo contrario, pues a pesar de compartir la misma carga genética de los enfermos, el 53\% de los gemelos no desarrolla conducta esquizofrénica.

Si a esto se le agrega que sólo un $20 \%$ de los que presentan esquizofrenia tienen un familiar en primer grado con enfermedad explícita, se puede concluir que es imposible sostener que un modelo mendeliano basado en un locus genético principal pueda ser responsable de esta enfermedad (Africa, Freudenreich y Schwartz, 2001).

Se ha propuesto, como explicación de esta discordancia, que aquellos gemelos que se presentan como fenotípicamente sanos, mantienen siempre la vulnerabilidad aunque ésta se muestre inexpresiva debido a que las experiencias ambientales de cada uno de los hermanos fueron diferentes; y además, que su capacidad para transmitir genéticamente la vulnerabilidad para desarrollar esquizofrenia a una eventual descendencia (Prescott y Gottesman, 1993) permanece intacta.

\section{Adopción de bijos de esquizofrénicos y su posterior evolución}

Por otra parte, las investigaciones realizadas con niños y niñas que fueron adoptados poco tiempo después del nacimiento y que más adelante desarrollaron esquizofrenia, han presentado hasta un 9\% de incidencia de la enfermedad entre sus ascendientes biológicos; en comparación con sólo un $2 \%$ de esquizofrenia entre los parientes consanguíneos de aquellos adoptados que no 
desarrollaron este trastorno. Las familias receptoras de la adopción, en cambio, mostraron una incidencia igual a la de la población general.

En este mismo estudio se encontró, además, que sólo un padre adoptivo desarrolló esquizofrenia después de ocurrida la adopción; que ninguno de los niños con padres biológicos no esquizofrénicos desarrolló la enfermedad; mientras que esto sí sucedió en la mayoría de los niños que tenían, al menos, un padre biológico con esquizofrenia (Africa, Freudenreich \& Schwartz, 2001).

Un meta-análisis de estos estudios de adopción, hecho con la intención de detectar la frecuencia de trastornos del espectro esquizofrénico -como son los trastornos paranoides, esquizoide, esquizotípico y limítrofe de la personalidad- (Prescott y Gottesman, 1993; Tsuang y Faraone, 2000; Herrera, 2003), ha mostrado que sus incidencias son más altas entre los miembros de la familia biológica del esquizofrénico que entre los integrantes de la familia adoptiva (Herrera, 2003; Prescott y Gottesman, 1993). Lo cual, aunque no avala la metodología de la culpabilización por parte de los terapeutas, que critican Africa y sus colaboradores (2001), indirectamente brinda apoyo a la teoría sistémica que hace mucho tiempo ha señalado cómo la ideología familiar (Kornblit, 1984) interviene en la génesis de la esquizofrenia. Este apoyo procede de la confirmación de que los familiares del paciente son esquizotáxicos y no están sanos como se pensaba en otra época y que, por lo tanto, son activamente responsables de las graves perturbaciones de la vinculación, de la individuación y de la comunicación que han sido descritas por Watzlawick, Beavin y Jackson (1983).

\section{La estructura de los genes candidatos}

Dado que la búsqueda del gen responsable de la enfermedad ha sido decepcionante (Africa, Freudenreich \& Schwartz, 2001), como lo han mostrado los resultados de amplias exploraciones del genoma, los investigadores han encontrado nuevas perspectivas de análisis. Se estudian, primero, los llamados genes candidatos, según sea su potencial implicación en la etiología del trastorno (Prescott y Gottesman, 1993; Herrera, 2003); y posteriormente, se aplican los denominados estudios de ligamiento, por medio de los que se identifican fragmentos restringidos del ADN para evaluar si existe algún alelo que correlacione con la esquizofrenia (Herrera, 2003; Prescott y Gottesman, 1993).

Con este método se han seleccionado algunos sectores cromosomales tales como los ubicados en los cromosomas 5, 6, 8, 11 y 22; pero también, se ha sugerido la posibilidad de que otros locus, como los ubicados en los brazos cortos de los cromosomas 9 y 20 (Herrera, 2003) puedan estar involucrados. Este tipo de estudios se ha realizado también en Costa Rica por investigadores del Centro de Investigaciones en Biología Celular y Molecular. Según Raventós y colaboradores (2002), los cromosomas que estarían ligados a la esquizofrenia dentro de la población costarricense serían el 1, 8, 13, 18 y 22. Pero, como ninguno de éstos por sí solo puede causar la esquizofrenia, esto ha conducido a la suposición de que varios genes podrían combinarse de diversas maneras en diferentes individuos para originar la enfermedad y ha creado la posibilidad para que se plantee un modelo que integre la participación de los factores medioambientales. 
La susceptibilidad resultante, entonces, parece distribuirse entre la población dentro del marco de un continum, donde existiría un extremo de alto riesgo y otro de bajo riesgo para la expresión del trastorno. Sin embargo, esta susceptibilidad no sería estática, puesto que podría variar con el tiempo, tanto en sentido negativo como en el positivo, dependiendo de las condiciones ambientales y de los estresores biológicos. A tal punto, que también sería posible una inactivación prolongada de la enfermedad, asociada a modificaciones moleculares de los genes, siempre y cuando puedan ser neutralizadas las noxas ambientales relacionadas con la expresión sintomática de la vulnerabilidad. De esta manera, existirían individuos que por tener menor susceptibilidad genética necesitasen estresores intensos para desarrollar el trastorno; mientras que otros, con mayor vulnerabilidad podrían desarrollarlo con sólo la exposición al estrés basal de la vida cotidiana (Herrera, 2003).

Estos estudios de genes candidatos y de ligamiento tienen, por consiguiente, el objetivo de demostrar el involucramiento génico en la etiología del trastorno, cuyas consecuencias podrían ser, por ejemplo, la codificación errónea de proteínas estructurales, de enzimas o de neurotransmisores; lo cual, le daría sustento etiológico a los mecanismos patogénicos (Heckers 2000) ya identificados en la esquizofrenia. Sin embargo, hasta ahora sólo se han obtenido resultados contradictorios, puesto que en conjunto no hay evidencias claras acerca de la implicación de variantes alélicas específicas de los receptores dopaminérgicos en la genética de la esquizofrenia y, tampoco, de las enzimas que intervienen en la degradación de la dopamina (Herrera, 2003).

A pesar de esto, por medio de la metodología del gen candidato y del alelo ligado se ha ensanchado el horizonte de la investigación etiopatogénica acerca de la esquizofrenia. De esta manera, los investigadores han podido examinar molecularmente un conjunto de genes putativos de la enfermedad y mediante la aplicación de técnicas de clonación y secuenciación están tratando de aislar las características genotípicas de los receptores o de las enzimas (Herrera, 2003; Prescott y Gottesman, 1993). Éstas podrían ser posteriormente comparadas con los genotipos de los receptores de dopamina que poseen los pacientes esquizofrénicos y con los que presentan las personas normales. Si se llegasen a demostrar diferencias moleculares se podrían lograr avances en el entendimiento de la enfermedad, así como en el diseño de medicamentos más efectivos y con menores efectos colaterales.

\section{La transmisibilidad de la esquirotaxia}

El término esquizotaxia fue introducido por Paul Meehl en 1962 para describir la predisposición genética a la esquizofrenia, la cual, según él, ocurría a causa de un defecto neurológico integrativo y sutil. Este autor propuso que los individuos esquizotáxicos podían desarrollar tanto esquizotipia o esquizofrenia, dependiendo de las circunstancias ambientales (Tsuang, Stone y Faraone, 2000).

Aunque la condición esquizotáxica no ha sido aceptada por la nomenclatura psiquiátrica, ésta puede asociarse, clínicamente, con este desconocido síndrome premórbido, que muy probablemente sea el sustrato neurobiológico de la esquizofrenia. Actualmente, después de más de 
tres décadas de investigación, la evidencia acumulada sugiere que la esquizotaxia es, de hecho, una condición clínica y un factor de riesgo o una señal que anunciaría el desarrollo de una psicosis.

El concepto de esquizotaxia de Tsuang, Stone y Faraone (2000), que se expone aquí, difiere de la visión de Meehl (citado por Tsuang, Stone y Faraone, 2000), puesto que los primeros entienden la etiología de la esquizotaxia como algo genético-ambiental, y no como algo puramente genético, como lo entendía el segundo; pero también, porque éstos creen que la etiología genética de la esquizotaxia resultaría mejor comprendida mediante un modelo multifactorial y poligénico que a través de un enfoque mendeliano (Tsuang, Stone y Faraone, 2000).

Según estos autores, los factores ambientales aparecen en escena junto con los genéticos en la producción de esquizotaxia. Por consiguiente, ellos proponen los dos aspectos siguientes como de gran relevancia para la formulación del síndrome esquizotáxico: a) es evidente que tanto los factores etiológicos, genéticos y ambientales, tienen consecuencias biológicas para el desarrollo temprano. Por esta razón, y a causa de estas consecuencias, es imposible separar los componentes puramente genéticos de aquellos originados en el ambiente; b) la esquizotaxia se originaría, congruentemente, por medio de los efectos de múltiples genes y de múltiples factores ambientales, los cuáles dependerían de condiciones heterogéneas tanto etiológicas como clínicas. La acción de estos factores etiológicos durante el desarrollo temprano parece señalar que la esquizotaxia es una condición ligada al desarrollo del sistema nervioso central.

En el esquema propuesto por Tsuang y sus colaboradores (2000) se describe cómo las vías etiológicas de la esquizotaxia-esquizofrenia parten de la vulnerabilidad genética, la cual sería activada por noxas ambientales tempranas, originando anomalías neurobiológicas responsables de algunas dificultades neuropsicológicas que podrían pasar desapercibidas para los clínicos. Cuando a éstas se le agregan otras noxas ambientales (tales como acontecimientos psicosociales negativos), el nuevo efecto sería una mayor estimulación de la condición esquizotáxica subyacente, lo cual produciría, primero, una variedad de síntomas prodrómicos, y finalmente, esquizofrenia. Estos eventos empeorarían la discapacidad de los individuos vulnerables para neutralizar, tanto conductual como neurobiológicamente, las fuentes de estrés y los retos de la vida cotidiana; promoviéndose de esta forma, los trastornos de la neuroarquitectura prefrontal que se observan en la segunda y en la tercera década de la vida de una persona con esquizofrenia.

Según este esquema, la aparición de la psicosis tendría un efecto tóxico para el cerebro del sujeto vulnerado y prodrómico, lo conduciría hacia la esquizofrenia crónica y más adelante, hacia la neurodegeneración.

Para Tsuang, Stone y Faraone (2000), entonces, la esquizotaxia es la forma de expresión más precisa que utilizan los genes para transmitir la vulnerabilidad. Ésta sería la razón por la que la psicosis aparece sólo cuando se reúnen la condición esquizotáxica y los factores ambientales desafortunados; y también, esta sería la ruta, por medio de la cual, se consolidaría la esquizofrenia (Tsuang, Stone y Faraone, 2000).

Por otra parte, en cuanto a las características clínicas de la esquizotaxia se han descubierto otros dos aspectos importantes: a) los síntomas negativos y, b) los déficit neuropsicológicos. Con respecto al primer aspecto, se ha encontrado, por medio de los estudios de familias y los de 
adopción, firme evidencia de que los parientes de las personas con esquizofrenia presentan alta incidencia de trastorno esquizotípico de la personalidad. Se ha encontrado, asimismo, que los familiares muestran alta incidencia de conductas como aislamiento social, dificultades serias para las relaciones interpersonales y pobreza de las experiencias afectivas. En el estudio de Gunderson (citado por Tsuang, Stone y Faraone, 2000), por ejemplo, se hallaron síntomas prepsicóticos, tales como ilusiones recurrentes y pensamiento mágico. Además, se ha reportado que en familias con un miembro esquizofrénico, los síntomas negativos (tales como afecto aplanado y abulia) están significativamente elevados, aunque la mayoría de sus integrantes no presenten síntomas positivos.

En cuanto a la segunda dimensión, se ha encontrado que los parientes no psicóticos de los pacientes esquizofrénicos muestran déficit variado de su funcionamiento cognitivo al compararlos con sujetos normales de control. Entre estas fallas se han destacado las deficiencias en atención auditiva, en memoria verbal y en funciones ejecutivas tales como la capacidad de abstracción. Estos defectos se han mostrado estables en estudios de seguimiento a cuatro años plazo. Análisis adicionales han mostrado que dentro del grupo de parientes se presenta una intercorrelación significativamente alta entre las tres funciones afectadas ya mencionadas, en comparación con grupos de control. Por esta razón, se cree que estas funciones neuropsicológicas perturbadas son indicadores claros de alto riesgo esquizofrenógeno para el grupo de los familiares de esquizofrénicos, en comparación con familiares de un grupo de control (Tsuang, Stone y Faraone, 2000).

Estos estudios sugieren que los trastornos neuropsicológicos en los parientes de pacientes esquizofrénicos son rasgos estables causados por el conjunto de genes relacionados con la predisposición. Ha resultado muy interesante, además, que cuando la muestra de parientes fue dividida en dos grupos, dependiendo de si tenían un solo pariente esquizofrénico o dos o más parientes con esquizofrenia, los resultados fueron que los integrantes del segundo grupo se mostraron afectados no sólo en las funciones ya identificadas, sino que también lo estaban en inteligencia, en memoria verbal retrógrada, en memoria no verbal y en memoria visual.

Estos hallazgos fueron particularmente congruentes con el modelo multifactorial de la esquizofrenia, que postula que no existe un solo gen ni un solo factor que pueda ser, aisladamente, responsable de la esquizofrenia. La enfermedad ocurre, por lo tanto, por el efecto combinado de un conjunto de genes y de múltiples factores ambientales que rebasan el umbral específico para cada persona. Por esta misma razón, se puede esperar que también exista un espectro de predisposición genética, donde la probabilidad de desarrollar esquizofrenia o algún otro de los trastornos relacionados con la esquizofrenia se incrementa dependiendo del aumento de la vulnerabilidad. De esta forma, sería muy probable que un grupo grande de familias albergue muchos genes esquizotáxicos en comparación con los que podrían detectarse en una familia aislada. Por otra parte, mientras que los síntomas negativos se presentan en alrededor del $20 \%$ al $50 \%$ y que la personalidad esquizotípica apenas en el 10\% de los parientes en primer grado de un paciente con esquizofrenia; la esquizotaxia en cambio, se muestra abrumadoramente presente entre estas mismas personas (Tsuang, Stone y Faraone, 2000). 
A lo largo de esta revisión panorámica sobre los diferentes estudios que investigan la genética de la esquizofrenia se ha destacado cómo la etiopatogenia de esta enfermedad es sumamente compleja, debido a sus intrincadas interconexiones de factores ambientales, psicodesarrollistas y genéticos (Africa, Freudenreich y Schwartz, 2001). A continuación, se expondrá la propuesta de un modelo no darwinista, el cual, sin negar para nada la participación de los factores biológicos, presenta una integración más fluida de todos los factores participantes, muy en congruencia con los principios epistemológicos de la cibernética

\section{Necesidad de un modelo no-darwinista de la conducta humana}

Para una mejor comprensión de la esquizofrenia y sus causas es necesario un modelo nodarwinista de la conducta humana. Este modelo se encuentra fundamentado en los tres postulados siguientes: (1) todos los individuos activan genes de desarrollo a través del contacto con su medio ambiente; lo cual es indispensable para lograr (2) la programación psicocibernética (ya sea en forma adecuada o inadecuada) de los sistemas cerebrales inmaduros; y para (3) la incorporación mnemocibernética de la historia socio-familiar como una constitución epigenética (Rof, 1984). A continuación se expone la fundamentación de cada uno de estos postulados.

\section{La activación de los genes de desarrollo por medio del ambiente}

En lo que se refiere a la conducta humana, no es posible considerar al genotipo como determinante del fenotipo, puesto que tal rigidez habría imposibilitado no sólo la conquista cultural humana, sino que también negaría el hecho de su constante etno-transformación. El genotipo, por consiguiente, debe ser comprendido como un horizonte de posibilidades caracterizado por su susceptibilidad para ser actualizado por la historia de interacción de los sujetos con su entorno particular (Jeammet et al, 1989). Este es el contexto de donde surge el concepto gen de desarrollo. A través de éste, puede comprenderse que un sujeto, que debuta culturalmente después de nacer, se presenta como un sistema genético que está en trance de completarse, por medio de la consolidación de un sistema nervioso que se desarrolla fraccionadamente y que depende de los estímulos neurofisiológicos que recibe de su ambiente para lograr su ulterior integración. Sólo así, podrá (o no podrá) madurar y estructurar sus regulaciones corticales más sutiles, en forma tal que su adaptación al complejo medio que le rodea sea lo más eficaz (Rof, 1984).

Este concepto refleja coherentemente la realidad observada: ningún infante recibe su medio ambiente en forma pasiva, puesto que desde su nacimiento es un modelador nato de su entorno al activar en todos los miembros de la familia (no sólo en su madre) las más antiguas huellas mnémicas de sus respectivos pasados infantiles. La presencia del infante irrumpe, desestructurando y reestructurando, todas las relaciones circulares preexistentes con sus demandas y con sus impulsos

de alejamiento. Su arribo a la vida familiar genera una tensión genética, que le lleva a completarse incorporando ambiente y suscitando ambiente (Rof, 1984). 
Toda la información que le es aportada después del nacimiento fluye dentro de ese dispositivo cibernético complejo que es su sistema nervioso central y es utilizada para aumentar la correspondencia entre su propio organismo y el medio ambiente que ya, genéticamente, estaba representado dentro de sí. La unidad de integración (Luria, 1984) producida por el encuentro entre estos dos mundos será la encargada del establecimiento de su Yo y también de la activación de todos los mecanismos (inmunitarios, endocrinos, neurovegetativos, entre otros) que participarán en el equilibramiento entre su mundo exterior y su mundo interior.

\section{La programación psicocibernética}

El segundo postulado del modelo parte del hecho de que a pesar de tener el cerebro humano especificaciones genéticas incuestionables, éste es capaz de lograr modificaciones funcionales inducidas por la programación a la que es sometida toda persona desde el momento de su nacimiento. Esta programación inicia con la simbiosis madre-hijo, dándole los primeros comandos sociales a los genes de desarrollo.

Estos genes, de una forma parecida a los que determinan el color de los ojos, también encierran en su código la inmadurez cerebral como una realidad de gran trascendencia. Este código es el encargado de prever la tutela diatrófica como el complemento de esta inmadurez, con el propósito de conducir la misión fundamental que tienen estos mismos genes en lo que al cerebro concierne: producir la adaptación al mundo exterior, haciendo que en el sistema nervioso de los seres humanos exista una representación dinámica del ambiente (Rof, 1984), que posea capacidad para la optimización y para la equilibración incrementante (Montserrat, 1985).

Por esto, la representación es propuesta, inicial y genéticamente, como un bosquejo. Pero más adelante este bosquejo se irá optimizando y equilibrando de forma lenta y progresiva, a través de las relaciones transaccionales (amorosas u hostiles) que ocurren durante el período de inmadurez cerebral. El sentido de esa afinación y perfeccionamiento dependerá, para cualquier adulto, de la aculturación específica que haya recibido y continúe recibiendo de parte de su entorno.

Como han dicho Pribram y Martin (1980), la maduración del sistema nervioso sirve a una más adecuada internalización del mundo exterior. Por medio de ésta, el cerebro codifica la información en el dominio de las frecuencias, no necesitando de ningún homúnculo para leer la huella de la memoria. Independientemente de que el origen de los datos proceda de cómo los sentidos perciben el mundo exterior o de que la información proceda desde el interior (por la experimentación de dolor emocional, por la expectativa de placer o por los mecanismos de atención), al final todos los estímulos activarían la huella de la memoria codificada en forma de frecuencias para producir imágenes y procesos mentales, las cuáles surgirían con la ayuda del caudal sensorial procedente del medio y a través de los circuitos locales del cerebro, como auténticos fantasmas energéticos al proyectarse holográficamente sobre la mente como si ésta fuera una pantalla.

Esta representación del ambiente en el cerebro no solamente abarcaría el campo tridimensional del espacio en que éste es escenificado, sino que también incluiría la dimensión temporal o histórica. El primer ambiente candidato para la internalización sería, sin duda, el vinculado con el 
objeto con quien se establece una relación básica, la cuál tendrá la función de impronta o la de un comando interpretativo de la realidad.

En el caso de los seres humanos, la inmadurez del sistema nervioso necesita de estímulos, porque sin éstos las neuronas se atrofiarían y se empobrecerían de las sustancias químicas fundamentales. No es que un recién nacido desvalido necesite apoyo o cariño, sino que ha de concebirse como un emisor-receptor de mensajes mediante los cuáles trata de incorporar a sus estructuras nerviosas aquellos últimos y refinados dispositivos que van a permitirle la máxima adaptación al mundo que le rodea. Esto se realiza por la incorporación, por un lado, de una red social que rebasa a la madre, porque está formada por las tradiciones colectivas y por las pautas educativas y sociales, que se encuentran insertas dentro de la matriz histórica de la realidad cultural; y por otra parte, por el juego de aproximación y de alejamiento ambivalentes que permite el desarrollo de la autonomía del sujeto (Rof, 1984).

Esta autonomía no puede lograrse, en el caso de los esquizofrénicos, puesto que sus genes de desarrollo no fueron adecuadamente programados para representar el mundo exterior consensuado y, por lo mismo, no pueden hacerse cargo de la realidad. Los trastornos comunicativos que caracterizan a sus familias dan lugar a fenómenos similares a los de la autoimnunidad, pues el Yo no tiene los recursos históricos para establecer límites entre lo que es sí mismo y lo que no lo es. Esto, que puede interpretarse como una incapacidad para categorizar, provoca en estos sujetos una discapacidad para formalizar expectativas y de que no puedan planear ni prever el futuro y, sin este valor predictivo, están también, discapacitados para hacerse cargo de sí mismos (Rof, 1984).

\section{La incorporación mnemocibernética de la bistoria sociofamiliar}

Finalmente, el tercer postulado del modelo implica la incorporación mnemocibernética de la historia socio-familiar. Como lo ha señalado Rof (1984), el cerebro humano es el órgano que incorpora historia, pero no como mero almacenamiento, sino de una manera tal que la historia, tanto la inmediata como la remota, la familiar y la de la cultura, se meten dentro del sujeto constituyéndolo de forma auténticamente hereditaria.

La vía por medio de la cual esta historia es incorporada en los genes ha sido propuesta por Sanders (1989) y Viana (1990). El primero señala que es posible imprimir información en las moléculas de ácido desoxirribonucleico (ADN) debido a sus cualidades semiconductoras. Viana, por otra parte, explica que esto es posible porque los átomos del $\mathrm{ADN}$ se comportan como si fuesen pequeños imanes (o espines magnéticos) que interactúan entre sí dentro de una red neuronal. De esta manera, son posibles el almacenamiento de experiencias, los mecanismos de reconocimiento y el aprendizaje (Viana 1990).

Sin embargo, a pesar de estos datos, por alguna extraña razón cuando se revisa la literatura médica o psicológica con respecto a la memoria, lo que se encuentra es una comprensión aislada del fenómeno (Viana, 1990; Drewe, 1980; Montserrat, 1985; Goldman, 2001; Winston, 1985; Adams y Victor, 1984), puesto que lo estudian desde la perspectiva de sus características neurofisiológicas y neuropsicológicas, pero con escasa o nula visión integradora, como si se desconociera el status de 
fundamental importancia que tiene la memoria para la constitución y el funcionamiento de la personalidad.

Un ejemplo de esta deficiencia puede captarse en el contenido explícito de esta cita de Drewe (1980):

Sin la memoria no tendríamos ningún conocimiento de los acontecimientos pasados y, por consiguiente, no podríamos adaptarnos plenamente a los cambios de nuestro medio ambiente. El conocimiento que tenemos de los acontecimientos anteriores nos proporciona una base para analizar e interpretar los acontecimientos actuales, para captar las relaciones entre ellos, y para planear una actividad apropiada (p.82).

Entre líneas se puede entender que toda la elaboración a la que Drewe se refiere es realizada por la personalidad de un individuo, pero no se explicita que ésta no existiría de no ser por la memoria dinámica de toda su historia subjetiva.

Lo que ocurre en la enfermedad de Alzheimer, según lo descrito por la APA (1997), es otro ejemplo de cómo cuando se destruyen los recuerdos, se inicia un proceso irreversible de egorrexis y de desintegración de la personalidad. A causa de esta enfermedad, como es bien sabido, se produce un ataque constante en contra de la unidad de integración (que es el Yo) y contra la personalidad, cuyas consecuencias son la disgregación de características como el juicio, la inteligencia, la voluntad, la afectividad y la sociabilidad, entre otras.

En consecuencia, por más que se demuestren factores genéticos y lesiones estructurales en la esquizofrenia (o en cualquier otro trastorno), tanto médicos como no médicos no deben olvidar que el ser humano desde que nace no es un objeto carente de conciencia que pueda sufrir lesiones o presentar vicios congénitos, sino algo mucho más vivo: es un ser consciente que evoluciona a lo largo de un proceso dinámico durante el cual se incorpora historia y espíritu a una sustancia biológica; donde su historia familiar, en particular, no sólo es algo exterior, sino que es algo que suscita una herencia pero que a la vez es suscitada por el hecho genético, ya que éste no es algo que está ahí dado tan sólo por la herencia biológica, sino que, además, es producto de una nueva herencia (in statu nascendi) que surge de la colisión amorosa y agresiva, del primer encuentro del sujeto con su entorno (Rof, 1984).

Desde el enfoque proporcionado por esta tercera hipótesis, resulta inaceptable el concepto de que a un gen preciso le corresponda un carácter comportamental concreto. Debe tenerse en cuenta que todo gen tiene un alelomorfo que actúa mediante acciones supresoras o inductoras, y que el efecto de un gen variará también en función de una expresividad y de una penetratividad moduladas por las influencias ambientales, haciendo imposible la producción de un mismo fenotipo. Dos ejemplos acerca de esta acción del medio son los que se muestran a continuación. Primero Cooper y Zubechs (citados por Jeammet et al, 1989) han demostrado que características conductuales de aprendizaje bien destacadas genéticamente y aparentemente propias de dos especies de ratas Bright (brillantes) y Dull (torpes) que producían patrones muy diferentes de errores en el aprendizaje de un trayecto de laberinto, podían variar bajo la influencia del ambiente. Así, los resultados de las dos especies que inicialmente eran muy distantes, se volvían parecidos según se sobreestimulara a las 
torpes o se subestimulara a las inteligentes (Jeammet et al, 1989). Estos resultados han sido corroborados por Rosenweig, Bennett y Diamond (1976), quienes han encontrado que las ratas mantenidas en ambientes estimulantes durante treinta días muestran cambios claros en la anatomía y los procesos químicos cerebrales cuando se las compara con otras mantenidas en ambientes apagados. Como segundo ejemplo se puede mencionar a Kandel (citado por Goldman, 2001), quien por medio de sus investigaciones con el caracol marino Aplysia, ha demostrado a través de microscopía electrónica que en las neuronas de éste se producen cambios funcionales y estructurales relacionados con el tipo de sensibilización a la que fue sometido. Por lo cual, concluyó que ocurría una modificación génica, correlacionada con una serie de cambios en los reguladores moleculares, que definitivamente habían sido causados por el aprendizaje. A raíz de estos estudios se enunciaron los siguientes cinco principios neurobiológicos: 1) todos los procesos mentales se derivan de operaciones cerebrales; 2) los genes y sus productos proteínicos son determinantes importantes de las interconexiones entre neuronas en el cerebro y de los detalles de su funcionamiento; 3) los genes alterados no explican, por sí mismos, toda la variación en una determinada enfermedad mental importante; 4) las alteraciones en la expresión de los genes, inducidas por el aprendizaje, dan lugar a cambios en los patrones de conexiones neuronales; y, 5) que cualquier tipo de condicionamiento de la conducta humana es capaz de producir cambios conductuales a largo plazo a causa de cambios inducidos en la expresión fenotípica de los genes (Goldman, 2001).

Mediante el modelo psicocibernético que se propone aquí es posible comprender, entonces, que toda conducta humana está sometida a una constante autorregulación cibernética entre lo que se forma orgánicamente (como correlato bioquímico) y la unidad-constituyente-de-subjetividad, que es la información acumulada epigenéticamente en el genoma, como un correlato biosocial.

\section{Discusión}

Habiendo expuesto los resultados de las investigaciones genéticas sobre la etiología de la esquizofrenia y propuesto el modelo alternativo para la mejor comprensión de la conducta humana, se han cumplido con los requisitos para emprender el análisis epistemológico planteado al principio. La discusión que se presenta a continuación se centra sobre dos puntos fundamentales: a) el examen epistémico de los modelos biologista y psicocibernético y, b) el examen de la visión estético-gnoseológica acerca de los errores de la objetividad.

\section{Análisis epistemológico de los modelos}

El modelo psicocibernético antes expuesto es coincidente con lo planteado por Montserrat (1985), quien también lo propone para entender el comportamiento humano en relación dialéctica con el entorno físico-social. Según este autor, la relación Hombre-Mundo raramente puede establecerse en un aquí y ahora, sino que, en general, se plantea como un vínculo entre el modelo 
del mundo interno y el del externo, que a su vez substituye la relación establecida entre el hombre y su exterior. Esta es la razón por la que ningún modelo se encontraría exento del efecto producido por los recuerdos y los proyectos, los cuáles influyen tanto como las percepciones del presente.

Por consiguiente, el modelo operatorio del mundo externo se forma poco a poco, con la ayuda de su entorno social, a medida que el sujeto se desarrolla. Primero, a través de sus órganos sensoriales aprende a captar el mundo externo y después de reunir toda la información procedente del mismo, la estructura en unidades cada vez más complejas, hasta constituir con ellas una totalidad coherente. Simultáneamente, todo el conjunto de la información interoceptiva y propioceptiva que es recibida en cada uno de los centros cerebrales es ordenado y almacenado de forma que constituya el modelo operatorio del mundo interno del sujeto.

Este procedimiento está respaldado por la investigación neuropsicológica. Según Rodríguez Delgado (citado por Montserrat, 1985), todo sujeto es al principio de su existencia, como un ser falto de corteza cerebral, no sólo porque hay muchas neuronas en formación, sino porque las ya existentes necesitan un entrenamiento prolongado e intensivo para memorizar e identificar los objetos que componen la realidad.

Así, aunque el mundo externo sea más o menos común a todos, el modelo que cada uno se forma tiene variaciones de un sujeto a otro, de acuerdo a su propia experiencia personal (que no es otra cosa que una sofisticada memoria histórica, compuesta de conjuntos escenográficos y guardada en forma de espín electromagnético y como información epigenética). De tal manera que, el MOME (Modelo Operatorio del Mundo Externo) varía no sólo por las diferencias geográficas y culturales en que el sujeto haya vivido, sino también, muy especialmente, por las condiciones simbólicas, representadas por las vivencias afectivas y la educación recibida.

Se puede decir, por tanto, que el MOME es el responsable del desarrollo ontogenético de un ser humano. Este modelo puede operar con varias metodologías. Una de ellas es la instrucción educativa, la cual puede ser entendida como un código de datos, creador de patrones convencionales de conducta, que son promovidos o reprimidos dependiendo de su grado de concordancia con la escala de valores sancionada por el contexto social específico en el que se desarrolla un sujeto dado.

Pero, aunque un modelo sea sólo una aproximación o una forma de simplificar e idealizar la realidad a través de un sistema de relaciones, es necesario que éste sea verdaderamente homeomorfo con la realidad, y no solamente isomorfo, para que lo establecido en el modelo sea transferible a la realidad y para que lo que se establezca en la realidad pueda reflejarse, a su vez, en el modelo (Montserrat, 1985). Esto sí ocurre con el modelo psicocibernético propuesto en este artículo, pero no con el psicobiológico utilizado en las investigaciones genéticas sobre la esquizofrenia, pues las características identificadas en el gen siguen teniendo la misma rigidez de la genética mendeliana y no exhiben aún la flexibilidad lamarquista que requiere un modelo homeomórfico.

Por otro lado, aunque todo enfoque psicobiológico debe ser monista y materialista, no puede dejar de asumir los temas clásicos propuestos por la psicología mentalista y espiritualista (Bunge, 1985). Estos temas, no acaban con la enumeración de la memoria, la imaginación, el amor o el odio, 
puesto que el tema más relevante es el de la flexibilidad epigenética para adaptarse al ambiente, algo que ha defendido especialmente la teoría sistémica. La investigación genética acerca de la esquizofrenia, aunque cumple parcialmente los criterios epistemológicos que señala Bunge (1985) en cuanto al desarrollo de una psicología fisiológica, porque podría explicar la conducta esquizofrénica en términos químicos, fallaría en cuanto a relacionarla adecuadamente con las variables físico-sociales (Bunge, 1985). En otras palabras, si bien el modelo biologista usado con la esquizofrenia parece suprimir, por una parte, el problema mente-cuerpo; por otra, genera la aparición de dos nuevos dualismos: mente en oposición a ambiente e información en oposición a materia.

No queda la menor duda de que el monismo materialista, que sostiene que la psique no es una sustancia sino un cierto conjunto de sucesos o procesos cerebrales (Bunge, 1985), es el futuro no sólo de las ciencias biológicas, sino que lo es también el de la psicología como ciencia social.

Pero, definitivamente, no basta con resolver el dualismo mente-cuerpo. La psicobiología lograría una victoria a medias con esto. El gran reto para las ciencias que tienen como objeto de estudio a la conducta humana es, después de alcanzar esta meta, la resolución del problema menteambiente y del problema materia-información. Sólo así se podría hablar con pleno sentido de acciones recíprocas entre distintas partes del cuerpo y entre las distintas partes del tejido social.

Las investigaciones de Tsuang, Stone y Faraone (2000) con respecto al involucramiento sintomático de toda la familia del esquizofrénico deberían ser enfocadas epigenéticamente y no ser interpretadas como la nueva ruta para aquellos modelos genéticos que escinden disimuladamente la relación biunívoca entre la mente y el ambiente. No debe olvidarse que la distinción entre salud y enfermedad es algo que el investigador añade artificiosamente a la realidad (Guinsberg, 1990) con la intención de conocerla, como ya ha sido señalado en este documento. Es una obligación del científico recordar que ese procedimiento se llevó a cabo, para recuperar el contexto significante de una conducta que, aunque tiene un claro correlato bioquímico, no es independiente de la urdimbre afectiva presente en el núcleo familiar.

A este respecto, es importante citar lo dicho por Freedman, Kaplan y Sadock (1982):

La importancia de los estudios de riesgo como posible medio para documentar el desarrollo de la esquizofrenia ha sido ampliamente reconocida. Sin embargo, hay una contribución (ausente) de estos estudios que no ha sido suficientemente destacada: la aportación de datos sobre el desarrollo normal y la invulnerabilidad al trastorno psiquiátrico. Esto parece ser un ejemplo de la innecesaria limitación que impone la tradicional orientación de la psiquiatría hacia la enfermedad: una orientación que tiende a prestar insuficiente atención a la manera como las personas vulnerables aprenden a hacer frente al riesgo, a adaptarse y a vencer (p.1103).

\section{Visión estética acerca de los errores de la objetividad}

El segundo aspecto de este análisis se refiere a los errores de la objetividad. Cuando se estudia cualquier fenómeno no se pueden evitar los "errores" generados por la misma objetividad con la que se examinan. La causa de esto es que, en todo campo de estudio, un investigador debe realizar 
simplificaciones de la realidad observada, aislando de diversas maneras, pero siempre con mucho rigor, algunos aspectos que posteriormente no podrán ser comprendidos plenamente si se mantienen separados de su contexto específico o de su descripción de proceso (Keeney, 1991).

Este planteamiento epistemológico es aplicado también por Montserrat (1985) para la construcción de los modelos que deben ser usados en la investigación científica. Según este autor, para construir cualquier modelo deben excluirse algunas propiedades que no se consideran esenciales, pero a otras se les debe destacar como muy representativas de la realidad que se investiga.

Esta metodología es, gnoseológicamente, indispensable debido a que en el mundo no existen distinciones. Por esto el observador debe crear un mundo de distinciones con el propósito de conocer algo (Keeney, 1991). Así, la única manera de conocer el sistema total carente de distinciones (pleroma), está basada en trazar una distinción dentro del seno del pleroma y, de esta forma, separar a una porción de éste para después denominarla y describirla como si fuera un objeto o un fenómeno independiente.

Pero, cuando se olvida que las distinciones fueron acciones agregadas por el observador al fenómeno u objeto estudiado surgen, entonces, los llamados "principios dormitivos", los cuáles se producen por la atribución de características que le pertenecen a la descripción del proceso en su totalidad pero que son aplicadas impropiamente al elemento segregado. Aunque esta estrategia tiene una gran importancia en casi todas las investigaciones científicas, puesto que puede guiar al planteamiento de hipótesis explicativas inéditas acerca de un fenómeno, también puede conducir a errores graves cuando se confunden el modelo y la realidad como si fuesen una sola cosa (Montserrat, 1985). Esto podría estar sucediendo cada vez que los hallazgos en el ámbito genético son utilizados para desvincular al paciente esquizofrénico con respecto al entorno sistémico compuesto por su familia y por su cultura.

Sin embargo, estos "errores" de objetividad son valiosos siempre y cuando puedan ser utilizados para alcanzar una realidad epistemológicamente superior. A la cual se tiene acceso mediante un proceso similar al de la correcta organización espacial de las piezas de un rompecabezas o al montaje y contemplación de una coreografía compuesta por la danza de interacción recíproca de cada una de las diferentes acciones simples (Keeney, 1991) que representan los bailarines. Estas acciones se podrían ejemplificar, en el caso de la esquizofrenia, mediante los síntomas negativos y las deficiencias neuropsicológicas características de las familias con un miembro enfermo, entre las que se podrían enumerar las ilusiones recurrentes, el pensamiento mágico, el aplanamiento afectivo y las deficiencias en atención auditiva. Así, el conjunto de los sujetos interactuantes con su bagaje de acciones simples constituiría el orden de recursión contextual donde se podría encontrar la categoría de acción conocida como esquizofrenia.

Por todo lo ya explicado, será legítimo que un investigador se proponga estudiar las modificaciones que acontecen en el nivel molecular de las personas con esquizofrenia, dado que acontecen también en ese nivel y de que toda conducta tiene un correlato de naturaleza material; pero también será legítimo que otro investigador desdeñe los cambios que tienen lugar en el nivel de las estructuras biológicas y que se concentre en los presupuestos y en los significantes que 
generan una respuesta subjetiva o una conducta convencional susceptible de codificación social, puesto que también ese mismo comportamiento tiene un correlato social. Pero, aunque sea posible que cada acto pueda estudiarse como un hecho social o como uno biológico, lo cierto es que existe una verdad gnoseológicamente mayor, la cual resulta de aunar las diferentes categorías de acción y de interacción que presentan las investigaciones parciales antedichas (Guimón, 1988).

De esta manera, se tiene que reconocer que los reduccionismos biologistas y psicologistas existen y son inevitables cuando se habla de conducta humana. Pero esto no puede eximir a ningún científico con respecto a su responsabilidad al adoptar hábitos equivocados de generalización al utilizar descripciones simbólicas como si fueran explicaciones operacionales (Keeney, 1991). En esquizofrenia estas descripciones han influido directa y operativamente en un cambio importante en la actitud de los clínicos hacia los pacientes: en otro tiempo eran más frecuentes los abordajes psicoterapéuticos individuales o familiares; en cambio, en los últimos veinte años estos abordajes se han restringido a causa de una extraña lectura de los textos y de los informes científicos.

Efectivamente, en éstos no es posible encontrar (Freedman, Kaplan y Sadock, 1982; Kolb, 1971; Hyman y Jenike, 1992; Flaherty, Channon y Davis, 1991; Shader, 1994; Prescott y Gottesman, 1993; Tsuang, Stone y Faraone, 2000; Lewis et al, 2003) como afirmación categórica que la esquizofrenia sea hereditaria. Más bien, todos coinciden en que "los factores genéticos no pueden explicar por sí solos la aparición de esquizofrenia” (Hyman y Jenike, 1992, p.47).

Pero, esto contrasta extrañamente con la atmósfera clínica y docente de la psiquiatría, la cual cualquiera puede comprobar. En este ámbito se afirma sin ninguna duda la etiología hereditaria y se actúa terapéuticamente según esta creencia, tanto en esquizofrenia como en trastorno bipolar. Por lo tanto, se hace necesario suponer que existe un mensaje latente en los informes científicos, a través del cual, parece establecerse de manera indudable la naturaleza hereditaria de estos trastornos.

Da la impresión de que los hallazgos, que no han variado sustancialmente en los últimos cuarenta años y que parecen un estribillo que dice incansablemente "los factores genéticos no pueden explicar por sí solos la aparición de esquizofrenia”, han producido una gran frustración dentro de los círculos científicos, pues siempre esperaron resultados contundentes, en lugar de los ambivalentes que se han obtenido.

\section{Conclusiones}

Después de haber revisado y analizado los modelos psicobiológico y psicocibernético se pueden obtener las siguientes conclusiones:

1) Que la investigación psicobiológica sobre la etiología de la esquizofrenia ha aportado pruebas acerca de la participación poligénica en el desarrollo de la enfermedad, la cual, sin embargo, no es suficiente por sí misma para explicar la aparición de ésta.

2) Que el modelo utilizado por esta investigación toma en cuenta solo en forma nominal a los factores psicosociales, porque éstos son puestos a girar alrededor del núcleo ocupado 
exclusivamente por los factores genéticos. De tal forma que, los factores psicosociales son mencionados en la introducción, olvidados mientras se despliega la actividad de laboratorio y recordados a regañadientes en la redacción de las conclusiones cuando los resultados no pueden darle sustento a la hipótesis de la independencia de los factores genéticos.

3) Que se podrían considerar los factores psicosociales con el mismo rango atribuido a los genéticos siempre y cuando se intente determinar cómo las variables psicosociales están asociadas a cambios bioquímicos de los genes involucrados. Algo que se ha usado en la investigación con animales pero no con seres humanos. También pueden ser tomados en serio estos factores, si se considera al ADN como un semiconductor capaz de almacenar, en forma de espín electromagnético, los comandos psicosociales que modulan la conducta y se emprende una investigación para lograr su lectura. Algo que sólo ha sido planteado por los relatos de cienciaficción.

4) Que la epistemología que usa la investigación genética en esquizofrenia continúa siendo lineal, aunque muestra cierta apertura hacia la contextualidad. Que el modelo de realidad que usa es isomórfico, lo cual le ha permitido resolver el dualismo mente-cuerpo. Sin embargo, el peso de su tradición mendeliana le impide incorporar en su modelo, los elementos lamarquistas que le permitirían alcanzar una modalidad homeomórfica. Debido a esto, es que no puede resolver los dualismos mente-ambiente y materia-información.

5) Que el descubrimiento de la esquizotaxia le ha permitido al modelo psicobiológico la resolución de la dualidad salud-enfermedad. Pero da la impresión de que no hay conciencia de este logro, puesto que contradice el posicionamiento político que ha asumido la psiquiatría. El concepto de esquizotaxia, íntimamente vinculado con los trastornos del espectro de la esquizofrenia, ha resultado ser un aporte valioso e innovador que revela cómo todos los integrantes de la familia del paciente están involucrados en la coreografía esquizofrénica, lo cual podría resucitar los abordajes psicoterapéuticos que fueron abandonados durante las últimas décadas del siglo XX (Tsuang, Stone y Faraone, 2000).

6) Que la investigación genética sobre la esquizofrenia podría ser indirectamente responsable de la lectura que han usado los clínicos en los últimos treinta años y, que los ha conducido a hacer cambios operacionales en el trato que se les da a los pacientes que presentan la enfermedad. Estos cambios se han fundamentado en la creencia clínica bastante generalizada de que la esquizofrenia es incuestionablemente hereditaria y que, por lo tanto, ningún psiquiatra debe pensar en tratar psicológicamente a las personas que presentan este trastorno.

7) Que la genética podría ser la creadora de un nuevo idealismo al darle más peso al correlato bioquímico que al social, con lo cual se podrían generalizar concepciones que eximen de responsabilidad a la sociedad y a la familia en cuanto a la generación de la conducta esquizofrénica. Esto podría ser una estrategia de ocultamiento de prácticas de control social, tal como lo han señalado Guimón (1988) y Guinsberg (1990).

8) Que el modelo psicobiológico debe convertirse en uno psicocibernético y que ambos deben asumir el reto de un proyecto de investigación que desentrañe los misterios del almacenamiento de la información capaz de configurar epigenéticamente a los sujetos y que relacione las 
modificaciones químicas y moleculares que se articulan como respuestas a los cambios ocurridos en el ambiente psicosocial.

\section{Referencias}

Adams, R.D. \& Victor, M. (1984). Principios de neurología. Barcelona: Reverté.

Africa, B, Freudenreich, O \& Schwartz, S.R. (2001). Trastornos esquizofrénicos. En Goldman, H., Psiquiatría general, pp.294-295.México: Manual Moderno.

Asociación Psiquiátrica Americana. (1997). Manual diagnóstico y estadístico de los trastornos mentales. Barcelona: Masson.

Bunge, M. (1985). Epistemología. Barcelona: Ariel.

Drewe, E. (1980). Memoria y aprendizaje. En Eysenck, H.J. \& Wilson, G.D. Texto de psicología humana. México: Manual Moderno.

Freedman, A., Kaplan, H.I. \& Sadock, B.J. (1982). Tratado de Psiquiatría. Barcelona: Salvat.

Guimón, J. (1988). Condicionamientos del diagnósticos psiquiátrico. En Guimón, J., Mezzich, J.E. \& Berrios, G.E. (Eds.). Diagnóstico en Psiquiatría. Barcelona: Salvat.

Guinsberg, E. (1990). Normalidad, conflicto psíquico, control social. México: Plaza \& Valdés.

Heckers, S. (2000). Neural models of schizophrenia. Dialogues in clinical neuroscience, 2(3), 267-279.

Herrera, M. (2003). Neurodesarrollo y esquizofrenia. México: Intersistemas.

Hyman, S.E. \& Jenike, M.A. (1992). Problemas clínicos en psiquiatría. Barcelona: Salvat.

Flaherty, J.A., Channon, R.A. \& Davis, J.M. (1991). Psiquiatría: diagnóstico y tratamiento. México: Médica Panamericana.

Jeammet, P.H., Reynaud, M \& Consoli, S. (1989). Psicología médica. Barcelona: Masson.

Keeney, B. (1991). Estética del cambio. Barcelona: Paidós.

Kolb, L. (1971). Psiquiatría clínica moderna. México: Prensa Médica Mexicana.

Kornblit, A. (1984). Semiótica de las relaciones familiares. Buenos Aires: Paidós.

Lewis, C.M. et al. (2003). Genome scan meta-analysis of schizophrenia and bipolar disorder. Part II: Schizophrenia. American Journal of Human Genetics, 73, 34-48.

López, C., Agudelo, A., Gómez, J., Ruiz, A. \& Ospina, J. (2001). Aspectos genéticos. En Téllez, J \& López, A. (Eds.). Aspectos neurocognoscitivos de la esquizofrenia. Bogotá: Nuevo Milenio.

Luria, A. (1984). El cerebro en acción. Barcelona: Martínez Roca.

Montserrat, S.(1985). Psicología y psicopatología cibernéticas. Barcelona: Herder.

Obiols, J.E. \& Obiols, J. (1989). Esquizofrenia. Barcelona: Martínez Roca.

Prescott, C.A. \& Gottesman, I. (1993). Genetically mediated vulnerability to Schizophrenia. Psychiatric Clinics $N A, 16(2), 245-267$.

Pribram, K.H. \& Martín, J. (1980). Cerebro, mente y holograma. Madrid: Alhambra.

Raventós, H. et al. (2002). Schizophrenia in the Costa Rican population: Preliminary findings on chromosomes 1,8,13 and 22. Trabajo presentado en el Congreso de la World Psychiatric Genetics Association. Bruselas.

Rof Carballo, J. (1984). Biología y psicoanálisis. Bilbao: Desclée de Brouwer.

Rosenzweig, M.R., Bennett, W.L. \& Diamond, M.C. (1976). Cambios cerebrales en respuesta a la experiencia. En Greenough, W.T., Psicobiología evolutiva: herencia, ambiente, comportamiento, pp.138-146. Barcelona: Fontanella.

Sanders, D. (1989). Informática: presente y futuro. México: McGraw-Hill.

Shader, R. (1994). Manual of psychiatric therapeutics. Boston: Little, Brown \& Co.

Tsuang, M.T. \& Stone, W.S. (2000). Schizophrenia: vulnerability versus disease. Dialogues in clinical Neuroscience, 2(3), 257-266.

Viana, L. (1990). Memoria natural y artificial. México: Fondo de Cultura Económica.

Watzlawick, P, Beavin, J.H. \& Jackson, D.D. (1983). Teoría de la comunicación humana. Barcelona: Herder.

Winston, J. (1987). Cerebro y psique. Barcelona: Salvat.

Artículo recibido: 11-8-2003 